\title{
LOS DISCURSOS DEL ODIO: LENGUAJE Y RACISMO EN EL CUSCO
}

\author{
THE SPEECHES OF HATE: LANGUAGE AND RACISM IN CUSCO \\ ORA SANKENARENTSI ANKANTAYETIRI ARA NINATANTSIKI: \\ AÑANE AISA ANKANTABAKAYETA O KANTANTSIPEE ARA \\ KOSKOKI(1)
}

\author{
José Solís Mora(2) \\ Universidad Nacional de San Antonio Abad del Cusco, Perú
}

\begin{abstract}
Resumen: Este artículo analiza como el racismo se construye con matices propios a partir de los hechos históricos nacionales en la ciudad de Cusco. En cada proceso, en el Perú y especialmente el Cusco, las personas hemos sido "entrenadas" para clasificar social y racialmente a las demás y también hemos aprendido a discriminar a esos otros que muestran algún rasgo cultural diferente al nuestro. Este entrenamiento se realiza a través de la socialización, donde el uso del lenguaje racista es un medio fundamental para la legitimación de estos discursos racistas. Esta semántica fue utilizada contra las poblaciones indígenas, migrantes y sectores populares para expresar odio, desprecio y sentimientos negativos por razones de prejuicios, estereotipos y mala socialización. En ese sentido las preguntas que guían el presente ensayo son: ¿Por qué siendo andinos somos racistas y discriminadores?, ¿por qué seguimos reproduciendo en pleno siglo XXI discursos y practicas racistas condenables? , ¿qué lenguaje usamos para racializar?
\end{abstract}

Palabras clave: Racismo, discriminación, lenguaje racista

Abstract: This article analyzes how racism is constructed with its own nuances from the national historical facts in the city of Cusco. In each process, in Peru and especially in Cusco, people have been "trained" to classify others socially and racially and we have also learned to discriminate against others who show some cultural trait different from our own. This training is done through socialization, where the use of acracist language is a fundamental piece of legitimizing these racist discourses. This semantics were used against indigenous populations, migrants

(1) Traducción: Yaneth Naty Antunez Camacho. Lengua originaria Ashaninka

(2) Antropólogo, Mgt en Desarrollo Rural, docente de la UNSAAC en la E.P de Antropología y Sociologia y en la escuela de posgrado. Consultor e investigador de la realidad andina sobre temas de desarrollo, pueblos originarios, resolución de conflictos y educación de adultos. Con 25 años de experiencia en comunidades indígenas andinas y amazónicas. Correo: jesus.solis@unsaac.edu.pe. 
and popular sectors to express hatred, contempt and negative feelings for reasons of prejudice, stereotypes and bad socialization. In this sense, the questions that guide this essay are: Why are we, as Andean people, racists and discriminators? Why do we continue to reproduce reprehensible racist discourses and practices in the 21 st century? and what language do we use to racialize?

Key words: Racism, discrimination, racist language

Kamtapachari: Oka sankenarentsi ameniro kempetachari kaantantsipe o akantabakayeta jero antantanakeari ashiketi otinkami okantasanotanakari perani anampitsiteki ara kipatsiki koskoki, ara kantanaintsari aka peroki aisati kipatsi koskoki, aro ashaninkape apankenatake akantantiari maronipe aisati kantantsipe akantabakayetari maronipe aisati ayotake akantimanayeti o ajitabakayeta añabakaka otsipape aborope kari anampisatipe .oka pankenarentsi antiro ara asaikajeitita ,antasanotirori añanesanori kantantsipe o akantabakayeta .oka sankenarentsi o ñanaberentsi kantantsipe o akantabakayeta .oka sankenarentsi yakojeitakero ikantimanajeitantiari isaikajeitinta pashini nampitsiki ,pokayetatsiri otsipape nampitsiki ,jayetatsiri otsipaki nampitsi o aisati saikajetatsiri inampiki ashi otimasanoti ninatantsi ,manintantsi aisati aroripe kari kametsatatsi ora ayojeitiri te onkametsate ,kenkeshiretantsipe aisa kari kametsatatsi asaikajeitita ,oka kantantsi ora sampitantsi oinijiro oka pankenarentsi.. kari kametsatatsi ora ayojeitiri te onkametsate, kenkeshiretantsipe aisa kari kametsatatsi asaikajeitita, oka kantantsi ora sampitantsi oinijiro oka pankenarentsi. ¿paitakia saekatsiri kachinkaiteriki akantajeta o akantimanabakayeta kantantsipe aisati ajitabakayeta. ¿paitakea antantarori irosati meeka aka siglo XXI kantantsipe aisati pankenarentsi kantantsi kari kametsatatsi 'kashitikantsi'.

Ñanasanotirori: kantantsipe, jitabakatsari, ajitabakayeta añane. 


\section{Antecedentes del racismo}

Para comprender el racismo es fundamental entender la colonialidad del poder entendida como los procesos de dominio, control opresión económica, dominación política y cultural por parte de los europeos a los pueblos indígenas de los países latinoamericanos desde el siglo XV hasta el siglo XXI. Donde el tema de la "raza" fue fundamento del patrón universal de diferenciación social básica y de dominación social, como lo señala Quijano (2000).

Quijano afirma que la idea de "raza" fue asumida por los conquistadores como el principal elemento constitutivo fundante de las relaciones de dominación que la conquista imponía. Sobre la base de dicho patrón de poder, fue clasificada la población de América y no solo fue eso, este patrón de dominación creó nuevas identidades (indígenas, mestizos, negros) con connotaciones raciales. Tales identidades fueron asociadas a las jerarquías y clasificaciones sociales correspondientes con el patrón de dominación colonial que continuó durante la república y la actual modernidad. En consecuencia, los pueblos sometidos fueron situados en una posición de inferioridad, subyugación, marginalidad y exclusión de la vida social y política, al igual que sus conocimientos y su cultura.

La "idea de la raza" fue una construcción social, significaba que los hombres eran desiguales naturalmente por razones genéticas, dicho concepto fue trasladado de la biología a la sociedad para justificar las desigualdades, la injusticia social y especialmente para organizar las sociedades. Es decir, a los blancos criollos oligarcas, por su condición racial fenotípica, les correspondía estar en los estratos dominantes porque eran "superiores"; en tanto que los indígenas y negros debían ocupar los estratos bajos por su condición de "inferioridad" racial y étnica. A partir de esta noción se construyen todos los discursos sobre la exclusión social, discriminación y la explotación económica y estos se insertaron dentro de las relaciones sociales, la estratificación social y las jerarquías políticas, lo que significó su impregnación en todas las estructuras de la sociedad colonial y actual. (Quijano, 2000).

Para el caso peruano, acorde con este modelo de dominación mundial, las elites oligarcas del siglo XIX diseñaron los mecanismos institucionales de opresión contra el indígena, su exclusión de la vida social, política y cultural del país, las mismas que se justificaban plenamente porque el "indio era incapaz, bruto, ocioso, torpe, sucio, ignorante", "una raza degenerada". No fueron casuales tampoco las normas de cuidar la "pureza racial" que se dio entre las familias aristócratas criollas para no contaminarse con mestizos u originarios; ideología que se mantuvo hasta antes de la reforma agraria. (Portocarrero, 1990).Para ejemplificar el pensamiento de la época, presentamos lo que decía el Dr. Sebastián Lorente, historiador, rector del colegio Guadalupe y asesor de educación del gobierno de Ramón Castilla. 
"Triste es confesarlo, pero la mayoría de los indios extraña a los progresos de la civilización, nos aflige con los vicios del estado salvaje. Yacen en la ignorancia, son cobardes, indolentes, incapaces de reconocer los beneficios, sin entrañas, holgazanes, rateros, sin respeto por la verdad, y sin ningún sentimiento elevado, vegetan en la miseria y en las preocupaciones, viven en la embriaguez y se duermen en la lascivia..." (Lorente 1855: en Romero, 2017; 5).

Pensamientos como este durante los siglos XIX y XX, así como todas las acciones de brutalidad, etnocidio, trabajos forzados, violaciones, expropiación de sus tierras y violencia física o cultural que ejercieron los latifundistas, hacendados, funcionarios del Estado, autoridades contra los indígenas andinos, como parte de los mecanismos de poder estatales y privados que se ejercieron impunemente desde los gobiernos y en la sociedad. A este esfuerzo contribuyo la ideología religiosa católica que justifico el abuso contra los indígenas bajo parámetros religiosos de resignación, perdón, culpabilidad y de la "gloria eterna" fuera de este mundo. Estas ideologías formaban parte de las relaciones sociales que se daban en las instituciones, la vida cotidiana y las jerarquías sociales y políticas como si fueran normales y naturales.

El racismo para el siglo XIX se constituyó en un instrumento de clasificación social de la población indígena y sirvió de fundamento de los roles sociales que fueron establecidos (los dominadores habían nacido para gobernar y los indios para obedecer y trabajar). Fue así como se construyó también el concepto social de la raza basado en la inferioridad racial y cultural del colonizado, donde las relaciones sociales estaban racializadas: unos tenían privilegios y los "otros" sin derechos, no eran considerados ciudadanos ni personas.Veamos lo que nos dice Alejandro Deustua, rector de la UNMSM, hacendado puneño, eminente miembro de la oligarquía, filósofo, varias veces diputado; quien reflexionaba:

"Las desgracias del país se deben a la raza indígena, que ha llegado en su descomposición síquica y que, por causa de la rigidez biológica de sus integrantes, que han terminado definitivamente su ciclo evolutivo... El indio vive sin interés alguno, bajo el imperio exclusivo de las necesidades materiales que satisface como las bestias, que son sus únicos modelos, y, peor que las bestias cuando las excitaciones del alcohol avivan la brutalidad de sus instintos sin disciplina. ... El indio no es, ni puede ser sino una máquina" (Deustua, libro "La cultura peruana", 1937, citado por Fuenzalida, 1975, 10; en Callirgos, 2015)

Portocarrero (2013) señala que la oligarquía costeña y sus aliados los gamonales serranos proponían que el ideal peruano de nación debía ser criollocosteño donde el indígena (al ser considerado bruto, falto de cultura y educación) no podía formar parte de lo peruano, y al no poder exterminarlo, lo único que quedaba era soportarlo, pero menospreciado y reprimido. Cotler (2005) por su parte indica que la clase "culta" del país sentía por el indio una mezcla de odio, 
miedo y desprecio al igual que los españoles y si bien impulsaron el capitalismo no tocaron en nada las bases ideológicas del racismo, la conservaron.

La invisibilización fue otra táctica racista de las élites dominantes peruanas, por cuanto nunca se tomó en cuenta la participación de los indígenas y sus descendientes en las decisiones políticas; no es casual que luego de la independencia durante los dos últimos siglos nunca hubo algún gobernante de origen indígena en el Perú o que los indígenas no hayan sido ministros, senadores, altos funcionarios o embajadores. Ninguna clase social ni sector de la sociedad urbana los tomó en cuenta, ellos eran solo "masa" manipulable.

Esta invisibilización también abarcó a la cultura, por cuanto las culturas indígenas (andinas y amazónicas) eran consideradas primitivas, inferiores; entonces el único modelo que debía predominar en la sociedad era la cultura dominante criollo-mestiza como cultura oficial sobre las culturas subordinadas. Pese a la reivindicación que hicieron los intelectuales cusqueños en los años 30 con el movimiento indigenista en el Perú, estas ideologías predominantes no fueron cuestionadas en su esencia y menos traducidas en alguna política pública. A las poblaciones indígenas se las siguió tratando como inferiores y atrasadas, incapaces de ser admitidas como ciudadanos por su condición de ser raza degenerada.

Con el desarrollo del capitalismo mundial y la implementación de las políticas neoliberales y la globalización a partir de los años 90, el discurso del racismo se fue adecuando, considerando que ya no era posible seguir postulando principios coloniales y republicanos del siglo XIX y de los años 30 y 40; debido a la universalización de los derechos humanos, el convenio 169-OIT, los movimientos sociales de lucha por la igualdad, la equidad y el aporte de las Ciencias Sociales a develar toda expresión discriminatoria, restrictiva o autoritaria. Pero la exclusión no desapareció, se mantienen los discursos racistas, la discriminación continua bajo nuevos ropajes ideológicos.

Las élites burguesas actuales nos han hecho creer que la globalización y la modernización transformaron al Perú en una Nación mestiza, blanca y civilizada siempre y cuando a los indígenas se los incorpore, se los blanquee, se lo desindigenice para que puedan asimilarse a la civilización, insertarse en la modernidad y disfrutar de sus beneficios. Si este es el único paradigma, entonces las políticas deben estar orientadas para que "todos formen parte de la sociedad nacional" (criolla-mestiza urbana). Y, supuestamente para que no exista racismo se debe promover el "mestizaje". Así, de esa manera se diluye cualquier diferencia racial. Leamos lo que dice Vargas Llosa.

"Los campesinos indios viven de una manera tan primitiva que la comunicación es prácticamente imposible. Solo cuando emigran a las ciudades tienen la oportunidad de mezclarse con el resto del Perú. El precio 
que tienen que pagar por la integración es alto, la renuncia a su cultura, su lenguaje, sus creencias, sus tradiciones, costumbres y la adopción de la cultura de sus antiguos patrones. Después de una generación se transforman en mestizos. Ya no son indios". (Vargas Llosa 1999, en De la Cadena, 2004

\section{Características del racismo en el Cusco}

El Cusco es una región muy especial a diferencia de otras zonas del país, porque en términos del imaginario nacional se considera que aquí es donde "se inicia la historia del Perú", por haber sido capital de la civilización Inca, de ahí que su transcendencia es evidente porque se mantienen vigentes elementos de la cultura de los Incas. Por ello, se conoce y reconoce al Cusco como región andina, quechua, indígena con un apego profundo a las montañas y a la cosmovisión andina. Imaginario que está en todos sus habitantes y que moviliza miles de personas cuando se trata de festejar el cumpleaños de la ciudad. Este criterio es fundamental porque todos los cusqueños de todas las clases sociales comparten y promueven la "cultura andina"(3) las costumbres, folklore y tradiciones tan propias de la región en todas las instancias de la vida social. Como ejemplo, el quechua es hablado por el $60 \%$ de los pobladores urbanos, cosa que no ocurre en otras ciudades de la sierra. $\mathrm{Ni}$ que decir de las fiestas patronales, cargos, festivales folclóricos, tradiciones y costumbres hasta la gastronomía; todas cargadas de elementos culturales sincréticos que conforman la idiosincrasia cusqueña.

Al estar todos impregnados del orgullo de ser herederos de la grandiosa civilización Inca, resulta paradójico que exista racismo y discriminación por razones culturales, que precisamente aluden a lo indígena, a lo andino. Dicho de otro modo: Si (casi) todos somos cobrizos, de pelo lacio, comemos mote, hacemos guatia(4), bailamos huayno, tomamos chicha, participamos en el Inti Raymi y mil cosas más heredadas de los indígenas. La pregunta es: ¿Por qué somos racistas y discriminadores contra ellos?, ¿por qué se cholea a la persona con rasgos indígenas?, ¿por qué sigue conservando ideologías coloniales?

Es tremendamente preocupante que el racismo en el Cusco se practique como un racismo anti indígena, cuando todos culturalmente provenimos de la matriz cultural andina. La primera respuesta que ensayamos va en sentido histórico: la causa está en la herencia colonial, republicana cuyos pensamientos oligárquicos racistas se han masificado y convertido en la ideología "oficial" de la sociedad peruana. La segunda es que los procesos de socialización ${ }^{(5)}$, actuales como la

(3) Entendida como la conjunción de elementos prehispánicos, coloniales españoles y de elementos de la modernidad que están amalgamados en las prácticas materiales y espirituales de indígenas y mestizos urbanos y rurales (Montoya, 1980).

(4) La huatia o guatia es un plato típico de los Andes que se prepara utilizando terrones o piedras calentadas con leña y fuego bajo las que se entierran los alimentos hasta que se cocinen. Esta forma de cocinar se utiliza en Perú, Bolivia,Argentina y Chile.

(5) La socialización entendida como al proceso a través del cual los seres humanos aprenden e interiorizan las normas y los valores de una determinada sociedad y viven como tal. Este proceso abarca la adquisición de la cultura de la sociedad en que vive como son las costumbres, creencias, tradiciones, imaginarios, símbolos, valores y normas. 
familia, la escuela, la religión y los medios de comunicación son las fuentes donde se forma, enseña y trasmiten esos prejuicios y estereotipos discriminadores que han sido internalizados por gran número de cusqueños andinos (urbano o rurales, con o sin ascendencia indígena) quienes lo reproducen profusamente en los colegios, instituciones, mercados, parques, buses y en todos los espacios sociales cuando inter actúan contra personas provenientes del sector rural o con migrantes.

Recordemos que durante la Colonia y la República la idea de la raza se asoció con los rasgos fenotípicos y biológicos, pero en nuestra época ha adquirido principalmente un carácter social y cultural. En ese marco, el racismo cusqueño está institucionalizado atravesando la cotidianidad de las personas y las estructuras sociales, tocando a las clases sociales, los roles y funciones, las jerarquías, el prestigio social; además de consolidar las relaciones de poder económico y político desde las élites. En esta estructura societal, "los que están arriba" se consideran con la facultad de discriminar, excluir y cholear al resto; en consecuencia, ese tipo de acciones deberían ser soportadas y aceptadas por "los de abajo". Todo ello compartido como si fuera normal y natural, parte de la forma de ser del cusqueño.

Lo más preocupante es que este imaginario se lo han creído casi todos porque los sistemas de socialización de la familia, la escuela, el barrio, la parroquia y la sociedad han sido impregnados de manera silenciosa y se han normalizado de ese modo(6) en la sociedad cusqueña. Esta es la peligrosidad del concepto de racismo y lo perverso que significa si es que no se lo recusa o interpela, los propios cusqueños vamos a seguir reproduciéndolo cotidianamente.

En este contexto, en el Departamento de Cusco y en el sur andino, se reprodujo el mismo imaginario racista, donde el gamonalismo era el grupo propietario de grandes extensiones de tierra con haciendas poco productivas con incipiente tecnificación, sin grandes inversiones agrarias; eran rentistas y su existencia como clase dominante fue porque la mano de obra indígena era barata. El campesino era considerado como un objeto (recurso humano) para trabajar las tierras del hacendado, trasladaba sus productos para ser comercializados bajo la condición de servidumbre, siendo sometidos a mecanismos de "condiciones" de trabajo como pongos y yanaconas viviendo en las condiciones absolutas de miseria y sometidos al paternalismo y dominio de los gamonales; estos ejercían el poder en su localidad y manejaban la vida pública de la ciudad capital. Los hacendados cusqueños eran quienes ocupan cargos públicos como alcaldes o diputados; decidían las obras publicas y pedían ayuda del Estado en los casos de rebelión indígena o recurrían al poder judicial para formalizar el despojo de tierras a las comunidades.

Los gamonales eran mestizos, fueron considerados "señores de la alta sociedad", de "familias ilustres" hablaban quechua y participaban también de

(6) Esto no niega la existencia de instancias de socialización que luchan contra la corriente, como la "educación alternativa", colectivos por los derechos indígenas, contra la violencia familiar, etc. 
fiestas con los campesinos, ejercían una violencia personalizada y un control intersubjetivo y de parentesco espiritual contra los indios. Es decir, se vivía en una sociedad estamental, clerical y autoritaria que produjo este racismo anti indígena elaborado sobre la base de la ideología del sistema de hacienda y la relación patrónsirviente que vino desde la Colonia y se consolidó con la República Aristocrática y dura hasta nuestros días. Si hay algo que distingue al Cusco del resto del Perú, es que en esta región se concentraron las relaciones de poder españoles más poderosas; no es casual tampoco que en la región se instalara la mayor cantidad de haciendas, las más crueles que tuvieron existencia hasta la reforma agraria(7). Por eso, no es casual que en el Cusco y el sur andino se concentraran el mayor número de haciendas y las condiciones de servidumbre ${ }^{(8)}$. Estos hechos históricos fueron las justificaciones para que las élites dominantes desaten sobre el indígena campesino y sus descendientes las más terribles formas de explotación, despojo, abuso, oprobio y racismo.

Todo esto se consolidó al reproducirse la ideología perversa de que "el indio era un ser inferior" y como tal, el racismo republicano buscó sustentar material y simbólicamente la superioridad del terrateniente (mestizo), de manera que justificaba y reproducía las relaciones de dominación y el ejercicio de poder de las élites sobre el resto, a fin de que la desigualdad social parezca normal y natural. Ideas que perduran hasta ahora y orientan las pautas para la actuación de las personas y son reproducidas por todos bajo la forma de patrones culturales legitimados socialmente.

Aquí un testimonio de un migrante andino:

"Soy de Chumbivilcas, una vez fui con mis primos al centro de la ciudad de Cusco y nos detuvimos a cenar en un restaurante turístico; mis primos estaban con su ropa típica de Chumbivilcas, un sombrero y una casaca. No quisieron atendernos y el mesero murmuro, aquí no se vende chuño. Así que nos retiramos y nos fuimos a la pollería a cenar." (Olger, 22 años)

Por tales razones, muchos cusqueños persisten en reproducir estos discursos y sentimientos de manera consciente o inconsciente porque fueron socializados así. Les enseñaron desde niños a ningunear, despreciar y humillar a personas de color diferente, de costumbres diferentes, de lengua diferente; es decir, mirar a los "otros"(9) como inferiores que componen la gran masa de indígenas

(7) Si bien no hay datos exactos, a partir de los datos del censo agropecuario de 1961 (INEI), estimamos que en el departamento existieron 7,500 haciendas con extensiones entre 50 a 500 ha (haciendas pequeñas y medianas) y 468 latifundios mayores a 500 ha. Haciendo aproximadamente 7,968 haciendas que representaban al 1.2\% de la población, quienes concentraban el $90 \%$ de la propiedad rural.

(8) Bajo formas de explotación como pongueaje, yanaconaje, arrendire, allegado, mañay, yanapako, semanero, aguilillo, yerbaje donde se mezclaban mecanismos de explotación económica, jerarquía social y la discriminación racial, bajo el control absoluto del poder gamonal.

(9) Concepto que hace referencia a personas de otras culturas inferiorizadas. 
y cholos migrantes ${ }^{(10)}$. Lamentablemente en el sistema educativo, centros de salud, comisarias, municipalidades, instituciones privadas, centros comerciales se continúan reproduciendo estas percepciones. Lo propio ocurre en formas equivocadas de crianza en los hogares y principalmente mediante los medios masivos de comunicación donde se van a difundir estereotipos y prejuicios racistas y excluyentes.

En las relaciones sociales cotidianas entre las personas se han creado "marcadores", o "indicadores" para diferenciar y establecer jerarquías sociales tomando como argumento el origen, posición socioeconómica, apellido, nivel de instrucción, forma de hablar el castellano, apariencia física, estilo de vida, apariencia o vestido, bajo los cuales muchos individuos racializan y se diferencian unos de otros mediante la "escala del choleamiento".(11)

Las prácticas de racismo también vienen acompañadas de discriminación, lo que implica prácticas que niegan o limitan derechos y oportunidades a determinados grupos, pero no a otros. En consecuencia, el trato diferenciado es un elemento clave del concepto de discriminación; a diferencia del racismo que es esencialmente una clasificación jerárquica; también se da la discriminación racista que es el trato diferenciado por razones fenotípicas, sociales y culturales.

En muchas personas migrantes la ideología racista va a ser asimilada y reproducida contra sus propios paisanos, en una suerte de "identificación con el agresor", donde el sujeto que es víctima de racismo termina por defender, justificare introyectar al agresor por una serie de razones que tiene que ver con su experiencia de vida personal, con su psicología, con sus emociones y sentimientos. Por tal razón, Gonzalo Portocarrero (1999) considera que "en nuestra sociedad el racismo es básicamente emotivo e inconsciente, y no tanto ideológico o doctrinario". Es un racismo tremendamente subjetivo y afectivo, donde muchas veces los migrantes racializados van a ser muchas veces los peores enemigos de sus semejantes y sumisos ante los poderosos; todo dependerá del momento y las razones para ello.

En resumen, el racismo peruano y cusqueño se caracteriza por:

- Considerar que la cultura andina es primitiva, irracional, pre lógica, llena de arcaísmos, constituyendo un obstáculo para la modernidad.

- Apelar a la genética y clasificación fenotípica para sustentar los agravios y humillaciones contra personas de otras culturas.

- Usar estereotipos de apariencia como vestido, tamaño, forma de hablar,

(10) "Indígena" es aquella persona cuya identidad está sustentada en sentirse étnicamente parte de la herencia cultural prehispánica, viven en comunidad y reproducen las tradiciones, practicas rurales, y su lazo es muy fuerte con la naturaleza. "Cholo" es el individuo que siendo de origen indígena asimila elementos de la cultura moderna y reproduce ambas culturas en la ciudad. Busca acceder a bienes y servicios y mejor calidad de vida. "Mestizo" es el citadino occidentalizado moderno.

(11) Proceso de clasificación y jerarquización social basado en criterios racializados (fenotípicos, culturales o económicos) que van a "ubicar" a las personas en escalones jerárquicos donde los individuos de un escalón "cholean" al del grado inferior, pero a su vez pueden ser "choleados" por los de escalones superiores. Esta clasificación es ideológico-simbólica sobre la base de marcadores racistas. 
de comportarse y origen cultural como justificación del vilipendio anti serrano.

- Usar el pretexto de la ocupación, tipo de trabajo y posición socioeconómica para racializar y discriminar a la persona humilde, desposeída quienes realizan trabajo manual o técnico.

- Calificar a priori al indígena como "salvaje", violento, agresivo cuando protesta, supuestamente por encontrarse alejado de la civilización.

- Considerar que el migrante al insertarse en la ciudad se "acriolla" y se convierte en rapaz, oportunista y aprovechador en perjuicio del citadino mestizo decente que es sorprendido por el "cholo vivo".

- Promover públicamente antinomias instaladas en el imaginario de la gente en el sentido de oponer: urbanos-rurales; limeños-provincianos, criollos-serranos; del valle-de la altura para remarcar las diferencias socioculturales de los grupos sociales.

- Apelar a la superioridad educativa del urbano-criollo-mestizo sobre el profesional andino provinciano para afirmar una supuesta calidad y mayor preparación.

\section{El lenguaje racista}

Toda la experiencia humana, personal y grupal está llena de emociones, sentimientos y valores, donde las conductas humanas se exteriorizan en todas sus dimensiones mediante el lenguaje, pero el lenguaje es pertinente a cada realidad social en términos societales y de las culturas que las contienen; pero también funciona en términos micro, a nivel de la interacción intrapersonal. Bajo esas condiciones (positivas o negativas) del entorno, se va usar determinado lenguaje para expresar los afectos, emociones y formas de entender el mundo. En el caso del racismo peruano, en general se va crear un lenguaje racista con connotaciones despectivos anti indígenas.

Veamos algunos ejemplos correspondientes a coyunturas bastante conocidas, de personajes públicos y mediatizados.

"Derrotar las ideologías absurdas, panteístas que creen que las paredes son dioses y que el aire es Dios, en fin, volver a esas formas de religiosidad donde se dice no toques ese cerro porque es Apu, está lleno del espíritu milenario y no sé qué cosas (...), si llegamos a eso, no hacemos nada, ni minería (...). Volvemos a este animismo primitivo. Yo pienso que los indios necesitan más educación y eso es un proceso de larga dimensión" (Alan García ante la oposición del pueblo aymara a la concesión minera en Puno, durante el "Aymarazo", 2007)

"Somos un país andino, es decir principalmente triste, allá los brasileros, colombianos son hiperactivos, alegres (...). Aquí tenemos 
indígenas que cosechan coca todavía (...) Todo ese hiperactivismo es racialfísico-genético (...) nosotros somos tristes y aquí siempre todo está mal, de verdad" (Alan García, 2009).

"¿Les vas a preguntar a las llamas y a las vicuñas sobre el TLC? (Ántero Flores Araoz Ministro de Alan García sobre la oposición de los campesinos para la aprobación del TLC (Tratado de Libre Comercio) con EEUU).

Los cusqueños se oponen al TLC porque en la altura no hay oxígeno y eso les dificulta pensar" (Pedro Pablo Kuczynsky, 2008)

"Nos detuvieron por ser cholos, pero nos acusaron de delincuentes" (cuatro jóvenes ciclistas detenidos por la Policía en el distrito de Miraflores, 2018).

"Allí donde y como lo ves; chato, cholo, mal vestido.......un capo" (referencia a un profesional premiado en el concurso de ciencia y tecnología).

"Yo no vivo en este país, vivo en Italia, me da vergüenza ser peruana (...) háblame bien, jsaca el mote jsaca el mote i (...). Acá hay tres serranos del serenazgo que me han faltado el respeto (...). Todavía me está filmando este indio (...). Pensará esta gente que soy igual que ellos, que soy del montón" (limeña de clase media ante personal de serenazgo en el mercado de Surco, 2019).

"QQuién eres tú?, ¿eres policía? Oye india no sabes con quien te has metido, chola de m..., so .... No me conoces, ¿sabes quién soy yo?, una profesional, tu patrona. (...). Tu eres una porquería al igual que tus hijos". (SuleykaAlatrista abogada frente a una señora vigía de la carretera variante de Uchumayo, a la cual golpeó con un palo. Fue denunciada por racismo pero el Poder Judicial archivó la denuncia, 2018).

"Este grupo de exaltados que la prensa entera llama indígenas han linchado a un periodista (...) es el tiempo de los matones y vándalos indígenas. (...). Si vienen de los bosques no tienen que indignarse por aumento del precio de la gasolina, ¿yo no sé cómo les afecta? Si son indígenas de verdad no creo que manejen un Audi o se movilicen en transporte público" (Jaime Bayli "El Observador", televisión de Miami, ante las movilizaciones indígenas en el Ecuador, 2019).

"Son gente sin nivel (...) las ligas departamentales ya no son mayoría pero son unidos. Serán cholitos, comen con la boca abierta en el hotel cinco estrellas, están vestidos con buzo y no con traje de dos mil dólares de Armani. (...). Porque donde te pueden sacar cinco soles te roban y te sacan mil soles, págame para el árbitro, son rapiña, pájaros fruteros" (Erick Osores, presentador deportivo Canal 4, hablando de los dirigentes provincianos, julio, 2019)

"Viajé a Lima con mi prima que es morenita igual que yo y nos fuimos a pasear por San Isidro, entramos a una cafetería a comprar tortas, las personas que atendían eran blancas y los consumidores también blancos, de pronto la gente nos empezó a mirar mal y las vendedoras nos dijeron 
que no nos atenderían, yo le pregunte ¿por qué?, dijeron ¿de dónde son? Les dijimos del Cusco, con razón, lo sospechábamos, serranas; si quieren que se les atienda será al último, primero la gente de Lima. Nosotras indignadas tuvimos que retirarnos." (Lucy, 27 años)

Este es el rostro feo del Perú, que muestra todos los días sus excrecencias en la cotidianidad, en las relaciones sociales llenas de ideologías y mentalidades acumuladas de siglos de desprecio y marginaciones racistas que son mayormente irracionales, que han logrado moldear sentimientos y pensamientos con una carga subjetiva tremendamente alienada que se descarga sobre personas culturalmente diferentes. También nos muestra el "Perú oficial", el discurso de las élites dominantes modernas, que consideran que "salvo el mercado, todo lo demás es ilusión", nada puede oponerse a la sacrosanta inversión privada, entonces se denosta y se apela a características biológicas y fenotipos racistas de los indígenas opositores ("perros del hortelano") quienes por su configuración genética degenerada no entienden el progreso y el desarrollo que vivimos.

El otro argumento -igualmente racista- es que los pueblos originarios poseen una cultura primitiva, mentalidad atrasada panteísta y un espíritu pasivo, conformista que nunca tuvieron lenguaje y esto hace que rechacen la modernidad. En todos los testimonios como se aprecia se apela al uso de un lenguaje racista lleno de adjetivos, improperios, sorna, agresión, desprecio y odio al "otro" por ser diferentes fenotípica, cultural, social, económica y educativamente. Responde a su vez a su visión cultural del mundo, es decir el conjunto de imágenes, ideologías, conocimientos, formas de explicar y entender la realidad. Todos los racistas mencionados obviamente tienen una visión absolutamente sesgada, llena de prejuicios, estereotipos, medias verdades, imaginarios y complejos inconscientes a partir de los cuales usan determinadas palabras según sea el contexto y los interlocutores, de manera directa o usando un medio de comunicación.

El racismo se vive, siente, practica y se sufre en términos de violencia verbal; estas situaciones se dan en escenarios y contextos donde concurren personas de distintas clases sociales y de grupos culturales diversos, que pese al mestizaje cultural ocurrido y no siendo las diferencias socioeconómicas y culturales tan abismales; sin embargo, en determinadas personas van a aflorar distingos raciales subjetivos, ideológicos y simbólicos para la diferenciación social. La forma de expresar dicha diferenciación será utilizando un lenguaje cargado de emociones de odio, desprecio y enojo.

"yo presencie el caso de una humilde familia campesina en el local del Totus, cuando se disponían a ingresar a una de las tiendas, inmediatamente las vendedoras llamaron a seguridad para no dejarlas ingresar y retirarlas del lugar por su manera de vestir y hablar. Esto causo el enojo de ellas y se produjo un conflicto, las vendedoras las insultaban 'india de m... chola arrastrada, pobretona' y otras cosas feas, humillándolas" (Ronald, 35 años). 
El lenguaje racista depende de un grupo para representarse a sí mismo, todo depende como dicho grupo o sociedad juzgue a los otros grupos sociales como "superiores" o "inferiores", "civilizados" o "atrasados". A partir de ahí se va usar el lenguaje con toda fuerza para hacer diferencias y con ella emergen los prejuicios ("terrorista", "indio"); por ello se dice que el lenguaje tiene la capacidad de definirse a sí mismo y de definir a los demás (Islas, 2005).

Pero en la sociedad el lenguaje no es la única ni la más importante manifestación de discriminación o racismo. Solo es un vehículo, el medio por el cual se expresa la desigualdad social objetiva, la cual a su vez está condicionada por relaciones de poder e interés de clase de las élites que buscan la continuidad de la jerarquía e injusticia social. Por eso el lenguaje se vuelve más insidioso cuando a una persona se la niega o rechaza por su origen cultural, por su apariencia, por el color de su piel, por sus costumbres. Las palabras importan, no tanto por lo que dicen sino por lo que hacen; porque no solo la manera como percibimos el mundo influye en nuestro lenguaje sino que el lenguaje que usamos afecta de manera profunda la forma como pensamos (Islas, 2005).

Por eso ciertos cusqueños tratan mal a los campesinos y migrantes de origen andino, con esto comunican todos sus prejuicios y estereotipos, con una carga emocional negativa y encono gratuito hacia ellos por su situación de vulnerabilidad histórica. Los rechazan sin mayor argumento, solo por su origen étnico y cultural; siendo víctimas de parodias, apodos y burlas.

A pesar que las normas societales se han democratizado y el éxito económico y/o social está permitido como parte de la movilidad social para los campesinos y migrantes que se han esforzado; los aspectos étnico-culturales no se perdonan ni pasan desapercibidos. En el cusqueño mestizo de clase media no se tolera que un "emergente" "venido de abajo" se codee con los urbanos mestizos bien nacidos, pese a que el migrante pueda tener refinada educación o éxito económico. Es muy común el uso de gestos, miradas, insinuaciones, indirectas, risas, chismes dentro de ambientes laborales, familiares, sociales y políticos, para comunicar usando lenguaje racista como: "igualado", "¿este quién es?", "no se pone en su lugar", "hay que ubicarlo", "¿qué se habrá creído?", "a este cholito hay que bajarle la llanta", "el indio refinado ya sacó la garra".

La lengua castellana codifica la realidad (de manera diversa) de acuerdo a las necesidades de la sociedad, a sus influencias ambientales y creencias. Con esa codificación los grupos categorizan a los grupos separándolos por diferencias socio económicas, de género, edad y otros. Desarrollan códigos que favorecen interpretaciones distintas o dotan a las mismas de connotaciones que no tienen en otros contextos (Islas, 2005). Por ello, el concepto de "cholo" tiene significaciónes distintas en el Cusco y en la costa. En Cusco, es más positiva, afectuosa, es un símbolo de identidad. 
La plata blanquea, pero de manera relativa, solo funciona en las actividades sociales, económicas y políticas donde se hace gala del derroche o la capacidad de gasto del migrante exitoso. Mas, en el nivel intersubjetivo, personal, de representaciones o el imaginario general "el cholo siempre será cholo, así tenga plata". Aquí juegan criterios de apellido, lugar de nacimiento, antecedentes de parentesco, apariencia, "el qué dirán" y en otros casos el color de la piel.

El uso del lenguaje es el medio por excelencia mediante el cual, los grupos sociales racistas y discriminadores van a comunicar sus discursos racistas, los estereotipos y los prejuicios acumulados durante sus años de socialización negativa. Aquí les presentamos algunos de los términos racistas más usados en Cusco ${ }^{(12)}$ :

a) Lenguajeracistaasociadoalaeducación: "indiosignorantes", "laignorancia es atrevida", "no se puede esperar otra cosa de ellos", "no sabe ponerse en su lugar", "gente analfabeta tenía que ser", "mal educados", "brutos", "torpes", "malcriados", "sucios", "no cumplen las leyes por su ignorancia"

b) Lenguaje racista asociado a la clase social: "tenían que ser pobretones", "solo saben estirar la mano", "ociosos" "no trabajan", "gente baja", "igualados", "indio con plata, Dios nos salve", "el cholo nunca olvida sus mañas", "al indio no se le puede dar poder", "es vengativo, "atroz", "violento", "no sabe gobernar", "no está preparado". "cholo con plata siempre es cholo", "Dios nos libre del indio leído".(13)

c) Lenguaje racista vinculado a lo étnico-cultural: "provinciano", "serrano", "quechua hablante", "campesino", "emergente", "chuto", "pata rajada", "Pachacútec", "cobrizo", "indio", "bajado", "ese guanaco", "estás Huamán", "folclórico", "de provincias altas", "chhuchu", "upichu", "chunchu"

d) Lenguaje racista vinculado a lo estético: "ese bebito es blanco, es una lindura", "ese muchacho tiene ojos verdes, que guapo", "es rubia, igual que su abuela extranjera", "qué raro ese niño es negrito ¿no será del gasfitero?", "tiene rasgos andinos, es bien feíto", "tienes que mejorar la raza, búscate un blancón"

Toda esta semántica se escucha profusamente a cada instante. Significa que los niños, jóvenes y personas que las escuchan al momento de racializar a otra persona, van a entender que forman parte de las estructuras de la sociedad cusqueña, del conjunto de normas sociales con las que funcionan las relaciones sociales cotidianas, porque los códigos lingüísticos repetidos continuamente han logrado naturalizarse, volverse normales y lo más preocupante considerarse como ciertos.

(12) Recogido en los grupos focales con los migrantes adultos.

(13) Recordemos cuando Evo Morales gano las elecciones en Bolivia el 2006, Mario Vargas Llosa escribía: "El es el emblemático criollo latinoamericano, vivo como una ardilla, trepador y ladero, con una vasta experiencia de manipular hombres y mujeres, adquirida en su larga trayectoria de dirigente cocalero y miembro de la aristocracia sindical". 
Dicha semantización lleva consigo una carga ideológica de parte del racista donde se entremezclan factores de clase, cultura y género. Carga ideológica manifiestada mediante insultos, desprecios, desplantes, agresiones verbales, físicas, psicológicas, chantajes y paternalismo; confirmando el etnocentrismo y autoritarismo de nuestra sociedad. La pregunta que se hacía un joven universitario era: ¿Cómo no ser racista si todos los días se aprende este lenguaje racializado?

En el imaginario del cusqueño -racista o no- de manera inconsciente y racional se ha instaurado un conjunto de jerarquizaciones estereotipadas resultado de su formación en la niñez y de todos los mensajes discriminadores de la sociedad que se encuentran "anclados" en su subconsciente, donde el lenguaje cobra valor cuando se establece una relación social de ejercicio de poder (laboral, político, social) automáticamente brota el stock de marcadores lingüísticos para clasificarse en dos dimensiones:

CRIOLLO-MESTIZO

INDIGENA, MIGRANTE
- Urbano, educado, cristiano, decente, bello, correcto

- Superior, civilizado, riqueza, progreso, globalizado: MODERNO

- Rural, ignorante, magico, bruto, feo, oscuro, pobre

- Inferior, primitivo, atraso, ignorancia: TRADICIONAL

Si el individuo se considera urbano, educado, decente, civilizado o globalizado inconscientemente se lo califica de "moderno", por consiguiente, se autodenomina como "criollo-mestizo". Viceversa, si la persona se considera o es tratada como rural, atrasado, oscuro, pobre o ignorante será visto como "indígena, migrante o tradicional". Por consiguiente, será objeto de racismo o discriminación.

Lo más preocupante es que este esquema maniqueo se va difundir en el ámbito privado y público, creando un imaginario tergiversado y manipulado impactando en la población que lo tomará como verdad y la reproducirá inconscientemente.

\section{Lenguaje racista expresado en el color "blanco"}

Desde el punto de vista simbólico, del imaginario colectivo, el blanqueamiento social tiene como figura emblemática al "color blanco" constituyéndose en uno de los estereotipos más usados desde tiempos del colonialismo europeo hasta nuestros días. No es casual que el eurocentrismo desarrollara su empresa imperialista a lo largo del siglo XIX bajo la ideología de la supremacía del blanco en todos los planos: el blanco dueño de tierras, bosques, recursos; los blancos portadores de la lengua castellana, inglesa o francesa; los blancos controladores del comercio mundial. Por ello, el uso del color "blanco" como un concepto polisémico totalizador que engloba contenidos relacionados a los bienes materiales, las personas, sus gustos y las relaciones sociales, todas están teñidas por el arquetipo "blanco". 
Aquí algunos ejemplos de cómo lo blanco se usa como paradigma y estereotipo:

- En el color de la piel: color aspiracional "todos desean ser blancos"; "la belleza femenina debe ser blanca, sino no es belleza"(14).

- En la cultura/sociedad: "sociedad blanca europea, americana"; "gringo blanco"

- En los medios de comunicación: los programas de TV trasmiten solo modelos blancos que dan alto rating, "el color blanco vende" con publicidad masiva de símbolos blancos cuyo paradigma es la familia peruana blanca de clase media acomodada.

- Modelo de consumo: consumo con distinción de autos, artefactos de la "línea blanca".

- En la estética: "lo blanco es bello"; signo de elegancia, distinción: adornos, vestidos, objetos.

- En los símbolos: "caballo blanco = conquista, gallardía, valentía".

- En el imaginario familiar:"niño blanco"= alegría, orgullo. Las referencias hacia el color de sus ojos y cabellos son frecuentes.

Ningún otro color ha sido tan promocionado en el mundo. Siendo esto así, el color blanco se va constituir en el paradigma ultra-pan mundial y referente de comparación con los otros colores de piel a los cuales va inferiorizar. Esto no es casual, por cuanto este estereotipo se inició con la expansión mundial del capitalismo del siglo XIX a raíz del enorme incremento de la industria y el proceso de acumulación de los grandes monopolios constituyendo las corporaciones y cártels, situación que coincidió con el reparto del mundo por las potencias imperialistas para apropiarse de los recursos naturales de Asia, África y América Latina. La justificación ideológica fue que se buscaba "civilizar" y llevar "el progreso" a los pueblos indígenas, tribus y culturas locales desde el paradigma civilizacióncomercio-cristianismo. Desde entonces, lo "blanco" se asoció al poder, a la economía mercantilista, a lo dominante. Los resultados de dicha empresa ya los conocemos: violencia, saqueo, matanzas, genocidios, invasión, corrupción, división y empobrecimiento de los países del tercer mundo. ${ }^{(15)}$

En este escenario, en el Perú después de la independencia, la piel blanca también fue el marcador más usado y motivo de distinción simbólica y material entre el criollo oligarca y los grupos dominados negros, mestizos e indígenas. El

(14) Recordemos la publicidad racista que fue bastante criticada en las redes sociales de una actriz que se ensucio la cara y se disfrazó de mujer andina cuyo rostro se blanqueaba con una crema "limpiadora"; cuyo mensaje subliminal era que las indígenas deben volverse blancas imaginariamente.

(15) Analizados de una manera maravillosa para África por Frantz Fanon en "Los condenados de la tierra"; y para nuestra realidad por Eduardo Galeano con "Las venas abiertas de América latina". 
modelo establecido estaba asociado por un lado al: "blanco-hacendado-patróngobernante" y por el otro: "negro-indígena-peón-sirviente-gobernado"; modelo que se impuso a toda la sociedad y que fue asumido y aceptado por todas las clases sociales, instalándose en su imaginario y formalizádonse en el sistema educativo, en las instituciones, en la religión, en las relaciones económicas, en la política y esencialmente en las culturas dominantes y subalternas.

En los siglos siguientes XIX-XX, se produjeron infinidad de mestizajes raciales entre individuos blancos, indígenas, mestizos y afros; a pesar de ello, la sociedad no se democratizó y el color blanco permaneció como paradigma a imitar o aspirar como una estrategia para posesionarse en la sociedad tan desigual o que los libere de exclusiones. Por ello, millones de individuos "no blancos" aspiran actualmente ser o volverse blancos, claro está, de manera simbólica, ilusoria, ideológica. No solo en el color de la piel sino en sus formas de vida, costumbres, consumo, gustos, pensamientos, valores, metas personales y prejuicios.Todo dependerá de su forma de inserción social, de sus vivencias personales y de los factores externos. Esto se evidencia principalmente en los sectores marginados de la sociedad, quienes, frente a las condiciones de desigualdad estructural, buscan "convertirse" culturalmente en blancos, de esa manera, van a sufrir menos discriminación y exclusión.

En este contexto, la necesidad de blanquearse responde al modelo de sociedad y al tipo de lenguaje utilizado que se objetiviza mediante slogans y símbolos que se revisten de paradigmas aspiracionales que forman parte de la cultura comunicacional de la sociedad.

Tal el caso de los siguientes mensajes:

- "compra, usa, desecha y otra vez compra" sinónimo de estatus social

- "para trabajar tienes que tener buena presencia"

- "tienes que ser competitivo", "eficiente", "eficaz"

- "solo los que tienen educación pueden acceder a cargos altos"

- "tienes que cambiar tu cultura para ser moderno"

- "solo desde la cultura moderna asimilas la ciencia y la tecnología"

Como se ve estos mensajes están dirigidos a la población indígena, provinciana, quechua hablante, quienes para no seguir sufriendo agravios, dolor emocional o sentirse mal por su condición de pobreza, color de piel, origen cultural o apellido, van a recurrir a estrategias de blanqueamiento social, donde la educación sirve para profesionalizarse o tecnificarse; además se debe trabajar esforzadamente para conseguir mayores ingresos o impulsar emprendimientos económicos; también se debe buscar ocupar cargos públicos o políticos y adquirir bienes y ostentarlos. Solo de esa manera el migrante andino será aceptado socialmente. 
El resultado que buscan muchos indígenas con este blanqueamiento social es ser aceptados social y culturalmente y no ser víctimas de discriminación y exclusión social. El problema es que al "blanquearse" el andino reproduce el modelo dominante, no lo cuestiona, se adapta a él y termina finalmente conservando y reproduciendo el sistema. Este proceso va desde la condición socialmente más inferiorizada de "indígena" que a medida que el individuo se va blanqueando va "ascendiendo" en su movilidad social, pero simbólicamente -siendo esto lo más importante- va dejando y adquiriendo al mismo tiempo una nueva condición socio cultural: de indígena a cholo y así sucesivamente hasta llegar a ser "mestizo"(16). Pero siempre con el paradigma de "progresar", "salir adelante" y dejar atrás un pasado sociocultural que elimine los estigmas discriminatorios.

\section{Lenguaje expresado en marcadores, etiquetas}

Normalmente el racismo en la ciudad Cusco capital| ${ }^{(17)}$ se va presentar bajo formas simbólicas, sutiles, disimuladas y muy rara vez de manera hiriente, torpe, agresiva como generalmente se da en Lima y ciudades de la costa contra los serranos. En el Cusco por lo general, el racismo se practica utilizando un lenguaje con marcadores de carácter principalmente sociocultural y en algunos casos muy específicos recurren a marcadores biológicos, físicos para mostrar su "diferencia de color de piel" como argumento de superioridad precisamente cultural y/o social.

El tema es que tratándose el Cusco como ciudad andina por excelencia, no debía existir expresiones de racismo contra los indígenas y sus descendientes migrantes; por el contrario debería ser una ciudad ejemplo de tolerancia e interculturalidad, por cuanto racialmente todos los cusqueños compartimos las mismas características fenotípicas y culturalmente se puede afirmar una "homogeneidad" en el sentido de que todas las clases sociales compartimos la misma admiración y valoración hacia la cultura andina o cultura inka. Además, la gran mayoría de los habitantes de la ciudad son parte de un cusqueñismo muy fuerte y están unidos en torno a la cultura andina y la lengua quechua ${ }^{(18)}$.

El problema está en descubrir y explicar ¿Por qué se desprecia tanto lo indígena?, ¿por qué hay discursos de odio?, ¿Por qué lo indígena sigue significando degradado, atraso, negativo y feo?,

Las personas que sufren discriminación y no menor racismo son los migrantes provincianos de origen quechua, los hijos de estos que estudian en

(16) Los pobladores cusqueños en términos raciales, étnicos y culturales casi nunca se identifican como "criollos", Este es un concepto reservado para los limeños, costeños, blancos, "pitucos". Gente racial y culturalmente muy diferentes al andino; además de ello, el imaginario los ve como hispanófilos, superficiales, "pura boca", dominantes, discriminadores, y extranjerizados que ostentan posiciones de poder económico, relaciones sociales influyentes y el poder político.

(17) El estudio abarca toda la región del Cusco, pero se realizó principalmente en la ciudad capital, con referencias a las ciudades intermedias como es Yauri, Sicuani y Quillabamba.

(18) Según el INEI, censo 2017, la población quechua hablante en la región es del 75\%, de los cuales en la ciudad lo hablan el $36 \%$ de sus habitantes. 
la ciudad, los residentes andinos ya establecidos que trabajan en los sectores informales, pequeños negocios y microempresas familiares; son los "cholos" que se han aculturado y que tienen rasgos étnico-raciales rápidamente identificables ${ }^{(19)}$ quienes viven en la Ciudad del Cusco y que interactúan con los miembros de las demás culturas criollo-mestizas y extranjeras y de otras clases sociales. Las expresiones de discriminación y/o racismo se dan mayormente de manera vertical de los citadinos mestizo-criollos hacia los migrantes provincianos, utilizando los siguientes marcadores lingüísticos:

\section{Tipos de marcadores lingüísticos racistas}

i. Nivel socioeconómico: que se sintetiza en los términos "pobre", "pobretón".

ii. Procedencia: referido al origen cultural del racializado como "gente del campo", "rural", "campesino, "indio", "folklórico".

iii. Apariencia, los rasgos estéticos:"feo","'bonito","atractivo","cuero","churro".

iv. Idioma, forma de hablar: "mote", "moteroso".

v. Nivel educativo: "preparado", "analfabeto", "ignorante".

vi. Influencias, relaciones: tener "vara", "recomendado".

vii. Género y sexismo: "tenía que ser mujer", "buena presencia”, "sexi”.

viii. Color de piel y rasgos fenotípicos: "blancón", "trigueño", "moreno", "negro", "marrón", "cara de inca".

Aquí vemos que los individuos que son socializados desde niños bajo etiquetas racistas, (aunque en el colegio o la casa les den mensajes no discriminatorios), van a aprender a reproducir los cánones racializados de uso común cuanto escuchan y ven que todos lo dicen y lo hacen. Es decir, si somos entrenados por diversos medios para efectuar clasificaciones raciales, además de estéticas y afectivas, entonces van a tener la certeza de que están actuando bien y estar convencidos que "las razas existen". (Bruce,2007).

"Un día sábado estuve en la plaza Túpac Amaru y había un señor del campo que haciendo compras le rozó de casualidad a una señora de la ciudad, ella reaccionó de una manera muy agresiva insultándolo "oye cholo fijate por donde caminas, porque no te regresas a tu puna, eres un indio". El campesino solo se calló al escuchar tantos insultos. Yo me quedé sorprendida, no pude casi hacer nada...(Ruth, 22 años).

Aquí se aprecia el uso de lenguaje referido a contenidos simbólicos que solo se hacen para la satisfacción personal subjetiva del individuo en términos que se "siente el mejor"(20) al tener la posibilidad de "subir su prestigio" en relación a su

(19) Con marcadores culturales como idioma, lugar de nacimiento, apellidos, vestido, costumbres, comida.

(20) El "mejor del barrio" o el más malo que se sabe odiado, pero a la vez temido. 
grupo, que no es tal, pero que funciona solo en el individuo, en su subjetividad alienada. En el Cusco existe el término de "acomplejado que se cree pituco" para designar a la persona que cholea a todo el mundo.

Estos aspectos se combinan con algunos estereotipos muy conocidos:

- "Te hicieron cholito" (te trataron de tonto).

- "No atiendo a provincias" (cuando no los de la gana de atender a alguien porque no vale la pena).

- "Estas Huamán" (frase vulgar que hace burla de un apellido inca muy común que se asocia a una palabra que denota imbecilidad o pobreza).

Estas formas expresan y desnudan de manera abierta como sutil, explicita e implícitamente como se ejerce la "diferencia hacia el otro" por razones estrictamente socioculturales, donde se pone en funcionamiento la maquinaria discriminatoria que evidencia todas las taras de la sociedad, sus mecanismos más excluyentes al decir "este espacio es mío", "esta cultura no te pertenece", "ustedes son un obstáculo para el progreso", "váyanse a vuestras provincias". Todo esto contradice los discursos de la democracia, de la igualdad ante la ley, la ciudadanía de todos y que todos vivimos bajo el mismo Estado de derecho.

Los grupos sociales mestizos y criollos urbanos al momento de relacionarse de manera vertical y asimétrica con los campesinos y migrantes van a recurrir a las categorías étnico-culturales para interactuar con ellos. Es decir primero los "escanean" bajo los marcadores indicados y, según sea esta "evaluación" podrán desarrollar relaciones sociales democráticas o discriminadoras con ellos. Si son migrantes o indígenas amigos entonces no ejercerán ningún maltrato racista, asumen actitudes paternalistas y los tratan lingüísticamente de "hijo", "hija", "don", "doña", "papacho", "mamacha". Por su parte el campesino o migrante tratará al mestizo de "papá", "mamá", "jefe”, jefa".

Tener apellidos como Quispe o Mamani, ser provinciano o tener piel cobriza no es impedimento para acceder a la profesionalización, a los cargos públicos o ser autoridades y alcanzar éxito económico como empresarios. En el Cusco, la aceptación cultural y social es abierta y general. El racismo se manifiesta de manera intersubjetiva y soterrada en la subjetividad, en los gestos, miradas cómplices, en los prejuicios alrededor de relaciones interpersonales en la cotidianeidad de sus vidas. "es cuando te dicen hazte más allá porque manchas mi ropa", "cuando te hacen oír que hueles mal", "esos paisanos son cochinos", "son ignorantes que se va hacer".

En la aplicación de prácticas racistas se usa profusamente un lenguaje y simbología racista, por eso, no es necesario que la persona discriminada vista o hable como indígena para ser racializada. Los hechos nos muestran que a pesar de que el mestizo-cholo está inserto en la modernidad y se esfuerza para tener éxito, "pesaran más" los marcadores culturales acompañados algunas veces de marcadores fenotípicos. Esto se manifiesta cuando el "blanqueamiento" le permite 
al individuo ir accediendo a los lugares que antes le eran prohibidos y gozar de los bienes, servicios, consumo y placeres; pero, por sus orígenes, apellido, costumbres, modo de hablar no va ser aceptado plenamente en dichos círculos. Siempre será "el cholo con plata", "igualado".

El racismo al funcionar de manera intersubjetiva y tocar los afectos, sentimientos y emociones llega a penetrar dentro de la psicología de las personas que muchas veces los "aplasta" moralmente con una baja autoestima e incapacidad de reaccionar ante el abuso; por el contrario, a veces, llegan a justificar y explicar dichos atropellos con argumentos normalizados y fatalistas, es decir terminan domesticados. Esto es más grave cuando el racializado pertenece a grupos subalternos urbano populares y reproduce el discurso del dominador al "cholear" a otro paisano semejante $o$ al indígena campesino, pese a que culturalmente comparten los mismos valores.

El lenguaje del "choleamiento" sirve para establecer jerarquías y posiciones sociales mediante la interacción de los marcadores socioculturales movibles y cambiantes. Por tal razón, existe un racismo urbano que se convierte en el nodo reproductor de prácticas racistas donde se entrelazan aspectos de clase, género y etnicidad.

\section{A modo de conclusión}

En el contexto actual, el sistema sociopolítico peruano no forma ciudadanos para que construyan relaciones de equidad, convivencia pacífica, respeto por los derechos de los demás; el sistema forma personas que solo vean un paradigma: el éxito económico y para alcanzar esto se debe usar las armas legales o ilegales a la mano, por eso el contexto cultural globalizado crea iconos, símbolos, valores, discursos y modos de vida orientados para que las personas desde niños aprendan a "ser competitivos", "aplasten al competidor como sea". En esa formación se insertan transversalmente contenidos racistas para remarcar las diferencias sociales y económicas. Lo que demuestra que el racismo cumple una función social y política de reproducir las desigualdades sociales y las relaciones de poder del sistema.

Es por tal razón que las élites han construido la existencia de los marcadores del "choleamiento" con la anuencia de las clases populares, teniendo como vehículo trasmisor al proceso de socialización; donde se trasmite también un lenguaje racista considerado normal, natural y parte de la realidad eterna e inmutable que se impregna dentro de los sistemas de creencia, imaginario e ideología de las personas. De modo que lo han incorporado en su vida cotidiana y relaciones sociales. Por dicha razón se acepta como reales y "verdaderos" de uso común y general. Aquí la explicación de porque es tan difícil erradicar el racismo en el Perú.

Aquí el lenguaje cumple dos funciones, la primera referencial o representativa: consiste en informar o transmitir un contenido o hecho tal como el emisor lo juzga, por tal razón expresa símbolos y significados tienen como fuente matriz la cultura de los pueblos que la originan. La segunda función es 
apelativa, influye, aconseja o llama la atención del receptor para que actúe de una determinada manera. Son precisamente ambas funciones las que se cumplen en el lenguaje racista, mediante este lenguaje, el racista comunica y trasmite mensajes con una carga ideológica, emocional y social muy fuerte, dependiendo qué palabra o concepto se diga, en qué momento y bajo qué contexto. Por ello, el lenguaje racista tiene una fuerza aplicativa potente y perjudicial por cuanto conflictúa las relaciones sociales y polariza a las personas.

\section{Referencias}

AGUIRRE, Carlos, (2018). Denle duro que no siente. Poder y transgresión en el Perú republicano. Fondo Editorial Pedagógico San Marcos. UNMSM, Lima.

BRUCE, Jorge, (2007). Nos habíamos choleado tanto. Psicoanálisis y racismo. Fondo editorial Universidad San Martin de Porres. Lima.

CALLIRGOS, Juan Carlos, (1993). El racismo. La cuestión del otro. DESCO. Lima.

DE LA CADENA, Marisol, (2004). Indígenas mestizos. Raza y cultura en el Cusco. IEP ediciones. Lima

GOMES, Paco, (2017). Indios, negros y otros indeseables. Capitalismo, racismo y exclusión en América Latina y el Caribe. Edic. Abya-Yala, BMZ, Quito.

HORBATH, Jorge y Gracia, María (editores), (2019). Indígenas en las ciudades de las Américas. Condiciones de vida, proceso de discriminación y lucha por la ciudadanía étnica. CLACSO, CONACYT, ECOSUR. Buenos Aires, Argentina.

ISLAS, Héctor, (2005). Lenguaje y discriminación. Consejo Nacional para prevenir la discriminación. Cuadernos de la igualdad. México DF.

KOGAN, L, (2012). La discriminación en el Perú: balance y desafíos. Universidad del Pacifico.

PORTOCARRERO, Gonzalo, (2009). Racismo, mestizaje y otros ensayos. Fondo Editorial del Congreso de la república. Lima.

PORTOCARRERO, Gonzalo, (2013). Sombras coloniales y globalización en el Perú de hoy. Red para el desarrollo de las Ciencias sociales. Lima.

PARIS, María Dolores, (2002). Estudios sobre racismo en América latina. Revista Política y Cultura, N.17. Universidad Autónoma Metropolitana. México DF.

QUIJANO, Aníbal, (2000). “Colonialidad del poder, eurocentrismo y América latina” en Edgardo Lander (comp.). La colonialidad del saber, eurocentrismo y ciencias sociales. CLACSO. Bs. As.

ZAVALA, Virginia y Back, Michele (editoras), (2017). Racismo y lenguaje. Fondo editorial PUCP. Lima. 